\title{
Commentary: No plan is perfect: It's about making choices
}

\author{
Joseph S. Coselli, MD, ${ }^{\mathrm{a}, \mathrm{b}, \mathrm{c}}$ and Alice Le Huu, MD ${ }^{\mathrm{a}, \mathrm{b}, \mathrm{c}}$
}

\footnotetext{
From the ${ }^{\mathrm{a} D i v i s i o n}$ of Cardiothoracic Surgery, Michael E. DeBakey Department of Surgery, Baylor College of Medicine, Houston, Tex; ${ }^{b}$ Department of Cardiovascular Surgery, Texas Heart Institute, Houston, Tex; and ${ }^{c}$ CHI St Luke's Health-Baylor St Luke's Medical Center, Houston, Tex.

Disclosures: Authors have nothing to disclose with regard to commercial support.

Received for publication Sept 25, 2018; accepted for publication Sept 26, 2018; available ahead of print Nov 16 , 2018.

Address for reprints: Joseph S. Coselli, MD, One Baylor Plaza, BCM 390, Houston, TX 77030 (E-mail: jcoselli@ bcm.edu).

J Thorac Cardiovasc Surg 2019;157:2137

$0022-5223 / \$ 36.00$

Copyright (C) 2018 by The American Association for Thoracic Surgery

https://doi.org/10.1016/j.jtcvs.2018.09.102
}

Although this study by Yang and coauthors ${ }^{1}$ is retrospective, it is of sufficient size to allow for reasonable conclusions. They apply specific criteria to facilitate a decision-making process intraoperatively. Their purpose is not to compare which of the 2 operations is superior (aortic root repair [ARr] vs aortic root replacement [ARR]), but rather it is to present their results of these 2 different approaches that are based on key criteria. For patients undergoing $\mathrm{ARr}$ in the setting of acute type A aortic dissection, an evidenced-based, decision-making algorithm is outlined.

In-hospital mortality was similar for ARR and $\mathrm{ARr}$ (8.5\% and $8.2 \%$, respectively), as were other postoperative morbidities, including new-onset renal failure, stroke, myocardial infarction, and sepsis. Regarding KaplanMeier survival analysis, survival was similar (62\% for ARR vs $65 \%$ for ARr at 10 years), as was the cumulative incidence of reoperation ( $11 \%$ for ARR vs $7 \%$ for $\mathrm{ARr}$ at 15 years). These results are somewhat better than those reported by Lee and colleagues ${ }^{2}$ in a recent analysis of the Society of Thoracic Surgeons Adult Cardiac Surgery Database presenting outcomes for patients with acute type A aortic dissection. The authors' results are also better than those reported by Conzelmann and colleagues, ${ }^{3}$ who analyzed mortality for patients with acute type A aortic dissection from the German Registry for Acute Aortic Dissection Type A.

The results of Yang and colleagues, ${ }^{1}$ who are affiliated with a dedicated, high-volume, aortic center, must be taken into context. These outstanding results are less likely to be reproduced in smaller programs in which aortic dissection is encountered far less frequently. The authors include results from patients undergoing valve-sparing ARR; it is important to note that this is a technically demanding operation, especially so in the setting of acute type A aortic dissection, which in most circumstances will command longer aortic crossclamp times. ${ }^{4}$ Care must be taken in

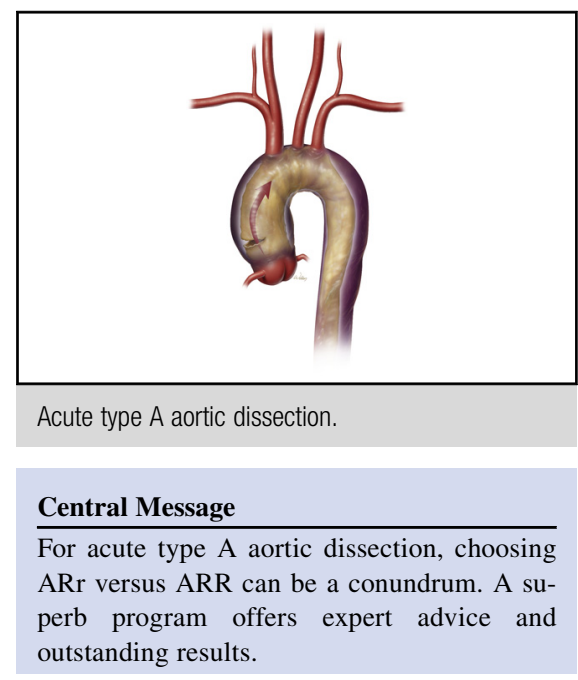

See Article page 2125 .

choosing procedures for perceived long-term benefits rather than demonstrated early survival benefits, particularly when undertaking a more complex approach to repair, such as ARR rather than $\mathrm{ARr}$ or valve-sparing ARR rather than the well-established Bentall procedure (ie, composite valve graft replacement). In the authors' current series, as well as presented in the literature in general, a limited ARr often yields good operative results in a high-risk setting where simply patient survival is the primary goal. When more is necessary, further evidence for making a good choice is substantially advanced by the current experience from the group at Michigan. ${ }^{1}$

\section{References}

1. Yang B, Norton EL, Hobbs R, Farhat L, Wu X, Hornsby WE, et al. Short- and long-term outcomes of aortic root repair versus replacement in patients undergoing acute type A aortic dissection repair: twenty-year experience. J Thorac Cardiovasc Surg. 2019;157:2125-36.

2. Lee TC, Kon Z, Cheema FH, Grau-Sepulveda MV, Englum B, Kim S, et al Contemporary management and outcomes of acute type A aortic dissection: an analysis of the STS adult cardiac surgery database. J Card Surg. 2018;33:7-18.

3. Conzelmann LO, Weigang E, Mehlhorn U, Abugameh A, Hoffmann I, Blettner M, et al. Mortality in patients with acute aortic dissection type A: analysis of pre- and intraoperative risk factors from the German Registry for Acute Aortic Dissection Type A (GERAADA). Eur J Cardiothorac Surg. 2016;49:e44-52.

4. Beckmann E, Martens A, Pertz J, Kaufeld T, Umminger J, Hanke JS, et al. Valvesparing David I procedure in acute aortic type A dissection: a 20-year experience with more than 100 patients. Eur J Cardiothorac Surg. 2017;52:319-24. 